\title{
Utility of forward and inverse modeling in 2D electric tomography for Hydrogeologic studies
}

\author{
Oualid Melouah $^{1}$ [D $\cdot$ Zerrouki Hichem $^{2}$
}

Received: 13 November 2019 / Accepted: 15 December 2020 / Published online: 14 January 2021

(c) The Author(s) 2021

\begin{abstract}
The choice of adequate techniques and arrays in electric tomography prospection is a difficult task; it depends generally on subsurface geology and the referred objective, this study is conducted in southern Algerian Sahara aquifer using 2D electric tomography techniques, the goal is testing different arrays configuration, using 2D model simulating the subsurface geology, the validated parameters from the theoretical study are applied to the real data, the results attest the usefulness of synthetic modeling choosing the correct parameters in geophysical prospection.
\end{abstract}

Keywords Electric tomography $\cdot$ Algerian Sahara $\cdot 2 \mathrm{D}$ modeling $\cdot$ Arrays $\cdot$ Synthetic modeling $\cdot$ Geophysical prospection

\section{Introduction}

The success of a geophysical campaign depends on data quality and the appropriate geophysical treatments applied to the data sets; in general cases, the 2D electric tomography (ERT) is widely regarded as a suitable tool to study the aquifer characteristics and ground water salinity (Nguyen et al. 2009; Adhikary et al. 2015).

The subsurface resistivity variations can be visualized through two dimensional resistivity pseudo-section created by inverting the observed data recorded at a time sequence.

The ERT technique is an important developement of electric imaging for subsurfaces mapping, the detailed interpretation of 2D resistivity distribution allowed to solve complex geological-geotechnical problems such as karst investigation (Sumanovac and Weisser 2001), bed-rock mapping, and

Oualid Melouah

Oualid411@yahoo.fr

Zerrouki Hichem

Geohichem@yahoo.fr

1 Laboratoire des Réservoirs Souterrains Pétroliers, Gaziers et Aquifères, Faculté des Hydrocarbures des Énergies Renouvelables et des Sciences de la Terre et de L'univers, Université Kasdi Merbah, BP 511, Route Ghardaïa, Ouargla, Algeria

2 Departement de Geologie, Faculté des Sciences de la Terres et Architecture, Université Larbi Ben Mhidi, Oum El Bouaghi, Algeria hydrogeological investigation, and it also has the ability to assess groundwater salinity (Adhikary et al. 2015) and to demarcate pollution plums in the ground water (Rao et al. 2013).

The present paper treats the effectiveness of synthetic modeling choosing the adequate parameters for hydrogeologic prospection, and seven arrays are tested: Wenner Alpha, Wenner Beta, Wenner Gamma, Schlumberger, Dipole-Dipole, Pole-Dipole, and Pole-Pole.

The used synthetic model represents two geologic layers with a resistivity value of 5 and $200 \Omega$ m representing probable salt lens included in a thick alluvial sediment.

The inversion process is affected by the data quality, for this two inversion methods are applied the L1 and the L2 least square inversion, the best results are obtained using the Wenner alpha and Schlumberger arrays with a electrode spacing of $5 \mathrm{~m}$ and 36 electrodes, and the time acquisition and the data resolution are considered during the comparison process.

The application to the real data aims to assess the alluvium aquifer water quality and to determine the suitability of the aquifer for various purposes, to delineate the location of the salt lenses by coupling forward modeling and the field investigation results. Consequently, this study serves as reference base to evaluate the rate of changement in shallow and deep water resources. 


\section{Data and methods}

The synthetic data used in this paper are generated using Res2DMOD software, and the data sets are exported as model files to RES2DINV software to be inverted and represented in pseudo-sections.

For the real data, a SAS ABEM 1000 résistivimètre and 4 electric cables reels are used to acquire the data points in manual mode, the total length of the profiles is from 150 to $240 \mathrm{~m}$, and the total depth is approximately $25 \mathrm{~m}$ (using 36 electrodes with spacing of $5 \mathrm{~m}$ ).

\section{Application to synthetic model}

Time-lapse inversion images produced under the salt bodies simulation in alluvial context demonstrate the effect of seven different arrays.

A two-layer synthetic model for the subsurface was developed based on geologic characteristics of drilled wells and geophysical data interpretation. The top model corresponds to the topographic surface and the bottom model is extended to $45 \mathrm{~m}$, and the salt bodies are located at 2 and $4 \mathrm{~m}$, respectively (Fig. 1).

In this work, RES2DMOD software is used to generate numerical model, the apparent resistivity model is divided into a series of homogenous and isotropic elements, resulting in a numerical model for whose the solution either the finite difference method (Dey and Morrison 1979; Loke 1994) or the finite element method (Smith and Vozzof 1984).

The tested forward modeling scenario is composed of two salt bodies with a resistivity value of $5 \Omega \mathrm{m}$; the second layer represents alluvium sediments with a value of $200 \Omega \mathrm{m}$, and resistivity values for both layers are chosen based on direct measuring of geological outcrops in different sites of the region.
These scenarios produce synthetic datasets that represents a simplified version of the geologic structure of the study area (Fig. 2). The results are inverted using least square inversion algorithm; seven arrays are tested to insight the geo-electrical signature of the salt bodies.

In each scenario, the two layers representation of the subsurface was forward modeled using a finite elements method with grid cells equal to $1 / 4$ the electrode spacing, to produce the most reliable and high-resolution characterization of subsurface resistivity distribution, electrodes configuration should produce a data sets with high data density and high signal to noise ratio (Loke and Barker 1996; Loke 2001; Dahlin and Zhou 2004).

Wenner Alpha (W- $\alpha$ ), Pole-Pole (PP), Dipole-Dipole (DD), Wenner Beta (W- $\beta$ ), Wenner Gamma (W- $\gamma$ ), Pole-Dipole (PD), and Wenner-Schlumberger (WS) arrays are frequently the most used for resistivity imaging (Fig. 3).

\section{Inversion}

Using pseudo-section starting model and L2 norm statistic for the iteration criteria; the L2 is defined as data misfit and is defined as the sum of the squared weighted data errors normalized by the number of measurement.

Least square inversion images produced in the cited conditions demonstrate the produced effects using seven different arrays, generally W- $\alpha$, DD, and WS arrays give good results delineating salt bodies limits.

In this paper, the Schlumberger results are shown for comparison. The given solutions in all the tested arrays are overestimation of the thickness of the salt bodies, this is probably due to the smoothing constraint employed by the inversion algorithm as part of the regularization method (Marescot 2004; Carey et al. 2017).

The PP and PD arrays represent moderate results delineating the geologic features of the model and reducing inversion artifacts effect (Fig. 4), this fact is due the

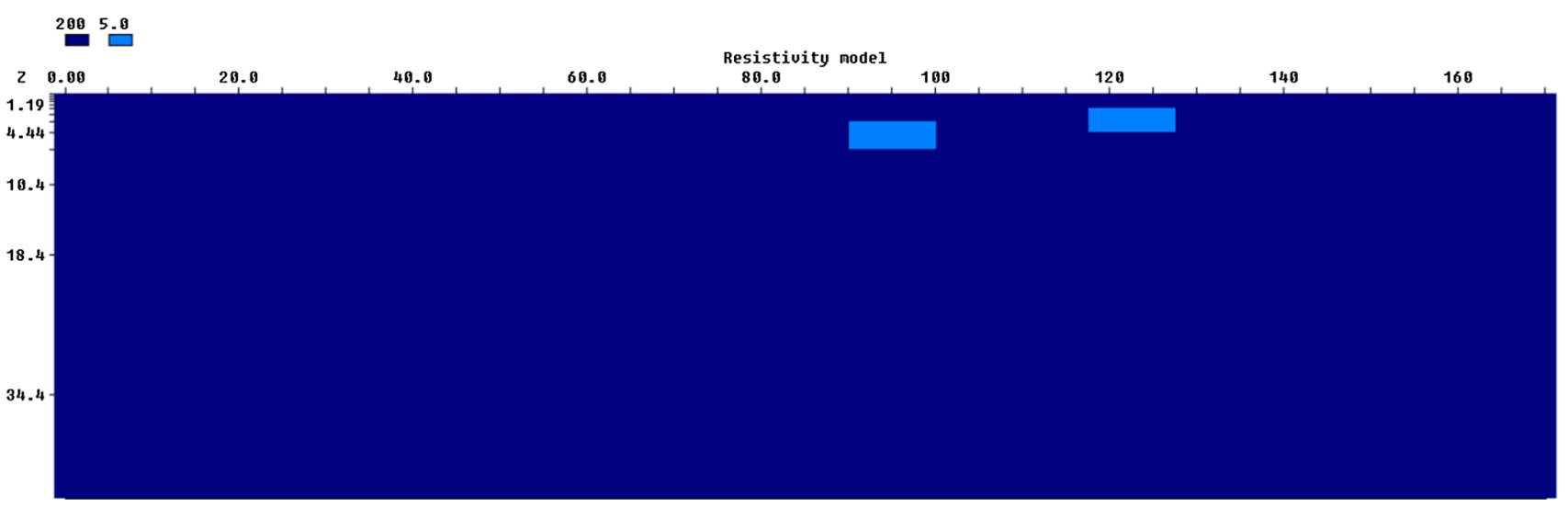

Fig. 1 Synthetic model of two layers, layer with $200 \Omega \mathrm{m}$ represent alluvium sediments, while layer with $5 \Omega \mathrm{m}$ represents salt bodies 

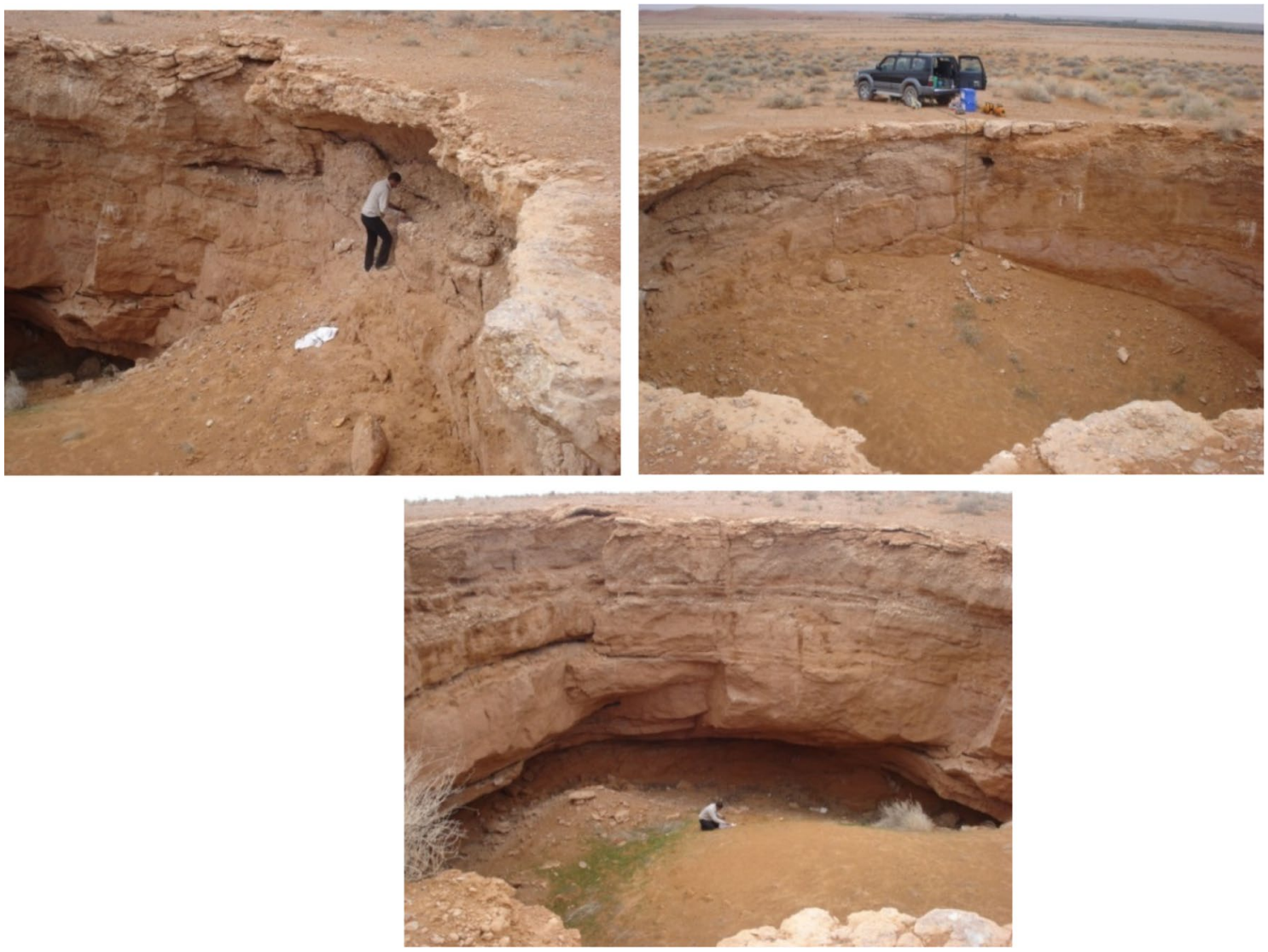

Fig. 2 Direct in situ resistivity measuring around the study area

important distance between potential electrodes (MN) and the low resolution in PP array, and the important sensibility of this array to telluric currents and noise can severally damage the data quality.

The PD array is an asymmetric device (injection electrodes placed a distance of five times the length of the array and termed the infinity electrode) and a symmetric object can appear as an asymmetric apparent resistivity anomaly, and this can affect the calculated model.

Generally, these two arrays are not used in 2D electric tomography and can give best results used in 3D imaging.

The DD array is better than PP and DP delineating the salt bodies, this can be attributed to the high sensitivity of DD array to lateral variation in resistivity (identifying vertical structures) than to the vertical contrasts (identifying horizontal structures), the average artifact values are higher than predicted in the synthetic model, and the position of the potential dipoles situated in the outside of the in line current dipole (Fig. 4) generates a small electric potential field gradients during ERT measurement which is difficult to solve during inversion process causing the high artifact values in the bottom profiles. Generally, the
PP, DD, and PD arrays generates more data points than the other arrays affecting considerably the acquisition time.

The $\mathrm{W}-\alpha, \mathrm{W}-\beta$, and $\mathrm{W}-\gamma$ are sensitive to vertical variation in resistivity (Identifying horizontal structures) than to the horizontal contrasts (identifying vertical structures) and $\mathrm{W}-\mathrm{S}$ array is a compromise between DD and Wenner array this gives high sensitivity to identify horizontal and vertical structures. The results show important reduction of inversion artifacts noise except for the $\mathrm{W}-\gamma$, the wenner $(\alpha, \beta, \gamma)$ and Schlumberger are single channel that makes one potential measurement in the midpoint of the array, and this generates a small number of data points and lacks of high gradient in the measured potentialities. The mean artifacts values are similar to the synthetic model values (difference between 5-20\%) and the edge contours are clearer than the used arrays.

Generally, the time acquisition factor is an important criteria choosing between resistivity arrays, additionally to the delineation of the salt bodies and ability to minimize inversion artifacts, from the given results in Fig. 4 and Fig. 5 the $\mathrm{W}-\alpha$ and Schlumberger arrays give the best results using the configuration shown in Table 1 which will be tested in real condition in the study area. 
Fig. 3 Frequently used arrays for 1D, 2D, 3D Electric imaging and sounding

\section{Dipole-Dipole}

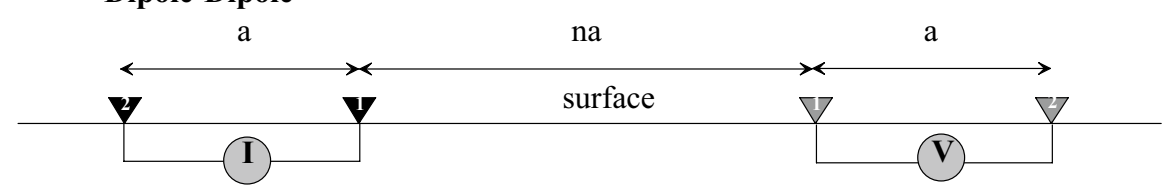

Pole-Dipole

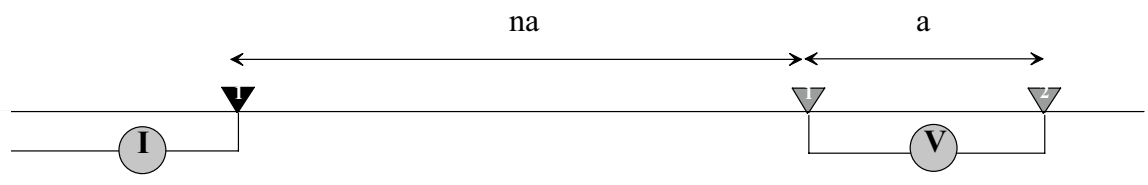

Pole-Pole

a

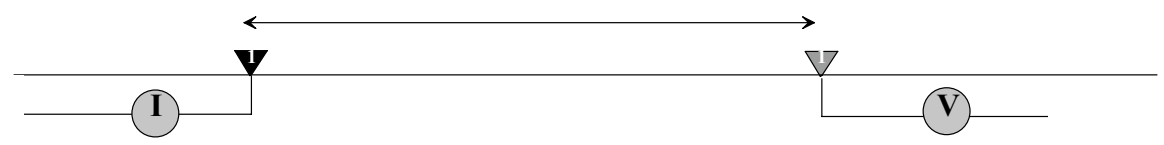

Wenner Beta

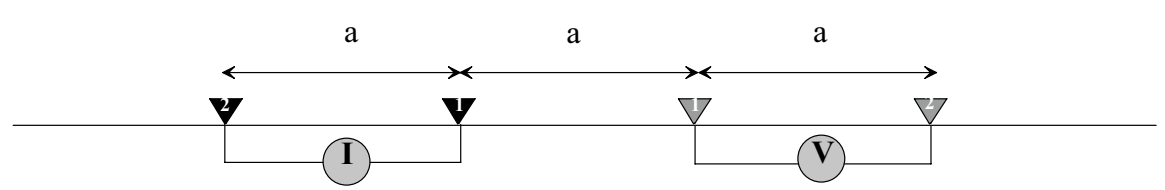

Wenner Gamma

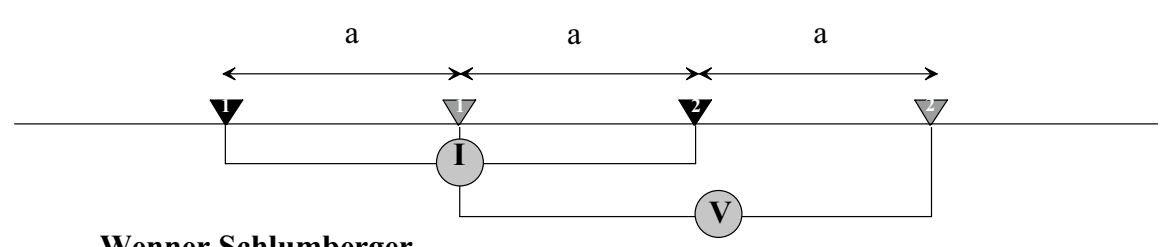

Wenner Schlumberger

na

a

na

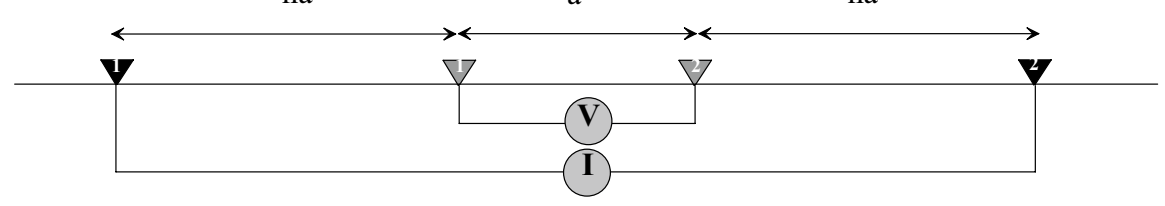

Wenner Alpha

a

a

a

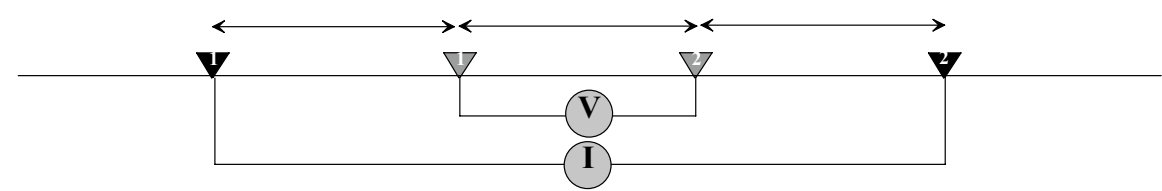

\section{Application to real data}

The data sets for the 2D ERT are treated and inverted using RES2DINV inversion code; wish is a non-linear optimization technique for determining $2 \mathrm{D}$ resistivity distribution.

The inversion is done using two schemes, namely a normal scheme (L2 norm, with smooth least square constraint) and robust schemes (L1 norm with smooth constrain), only the best solutions are exposed in this work. Most ERT profiles had been processed using standard least square inversion which minimizes the square of the difference between the observed and the computed apparent resistivity except for palm 1, palm 3 profiles treated using the robust inversion wish is less sensitive to very noisy data points but might give higher RMS error (Table 2).

For each profile, the inversion is stopped when the improvement in the RMS error is not significant, most profiles reach a satisfying RMS error after 5-25 iterations, the 
Fig. 4 Synthetic response of the synthetic model using conventional electric arrays, a Wenner Alpha, b Pole-Pole, and c Dipole-Dipole (a)

Resistivity (ohm.m)

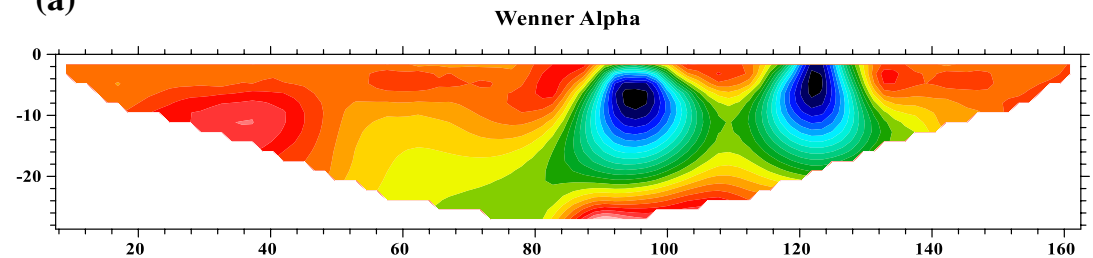

(b)

Pole Pole

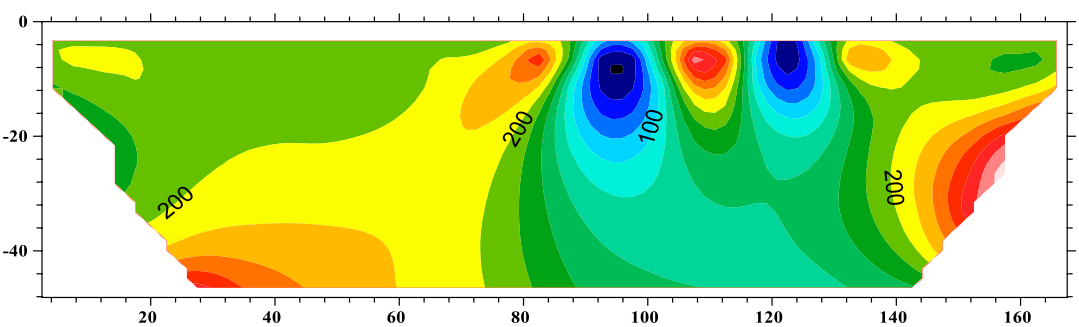

Dipole Dipole

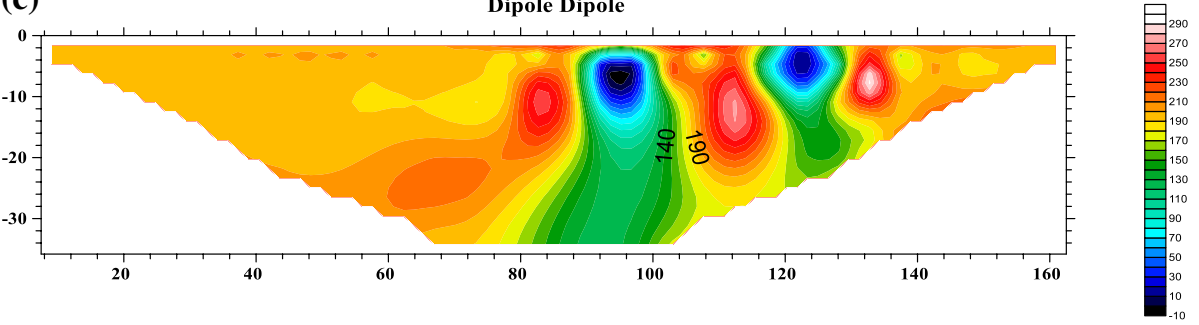

topographic corrections are included in TXT files and processed during inversion.

\section{Profiles palm 1 and palm 2}

The profiles 1 and 2 are presented together to map the possible extension of salt bodies in the lower part of the study area, the high salinity degree in the near wells confirms this probability; both profiles 1 and 2 are oriented NW-SE direction and is $175 \mathrm{~m}$ length with $5 \mathrm{~m}$ electrode spacing.

Figure 6 displays resistivity pseudo-section from the standard and robust inversion with smoothness constrain for the Wenner alpha array

Generally, the first layer is a hard surface characterized by high resistivity values (500-800 $\Omega \mathrm{m}$ ), the second layer represents the alluvium aquifer with low resistivity values due to high salinity water in the formation, salt bodies are very low electric resistivity $(2-7 \Omega \mathrm{m})$ located at the $\mathrm{X}, \mathrm{Z}$ position, respectively, $20 \mathrm{~m}, 4 \mathrm{~m}$ for the salt body $1,100 \mathrm{~m}$, $4 \mathrm{~m}$ for the salt body $2,124 \mathrm{~m}, 2 \mathrm{~m}$ for the salt body 3 , and $152 \mathrm{~m}, 5 \mathrm{~m}$ for the salt body 4 . The dry sandstone in the study area has a electric resistivity values of $90-140 \Omega \mathrm{m}$ the saltwater infiltration through fractures change considerably the resistivity values of the bedrock the sandstone bedrock located at $12-14 \mathrm{~m}$ depth with moderate resistivity values $30-70 \Omega \mathrm{m}$.
Figure 6 displays the least square inversion results for palm 2 profile, the shallow high resistivity layer appears to be thick compared to palm 1 profile, the second layer resistivity is $13-25 \Omega \mathrm{m}$ represents alluvial aquifer with less salinity degree than palm 1 profile; the bedrock is located at $14 \mathrm{~m}$ with resistivity values of $35-90 \Omega \mathrm{m}$.

The fractures density, the degree of alteration, and the quality of the matrices cementing the sandstone are the main factors controlling the changes in resistivity values; in the study area, the sandstone matrices are clayey in the northern part while is gypseous in the lower part in the accumulation basin.

\section{Profile palm 3}

Oriented to $\mathrm{N} 135^{\circ}$ with total length of $165 \mathrm{~m}$, the first layer with high resistivity values $35-300 \Omega \mathrm{m}$ the layer is less thick $(1.5-2 \mathrm{~m})$ in the western part of the profile and thick in its eastern and central part $(4 \mathrm{~m})$, this layer is crossed by a vertical heterogeneity representing a filled sinkhole $(16 \mathrm{~m}$ in width) or a fractured zone with moderate resistivity values.

The alluvial aquifer is characterized by electric resistivity values ranges between $10-35 \Omega \mathrm{m}$ crossed vertically by the same layer until $18 \mathrm{~m}$ depth, salt bodies are very low electric resistivity $(0.3-5 \Omega \mathrm{m})$ located at the $\mathrm{X}, \mathrm{Z}$ position, respectively, $20 \mathrm{~m}, 3 \mathrm{~m}$ for the salt body $1,50 \mathrm{~m}$, 
Fig. 5 Synthetic response of the synthetic model using conventional electric arrays, a Wenner Beta, b Wenner Gamma, c

Pole-Dipole, and d WennerSchlumberger

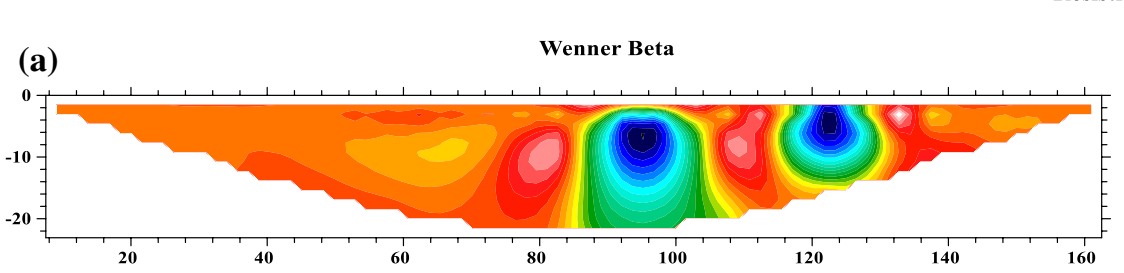

(b)

Wenner Gamma

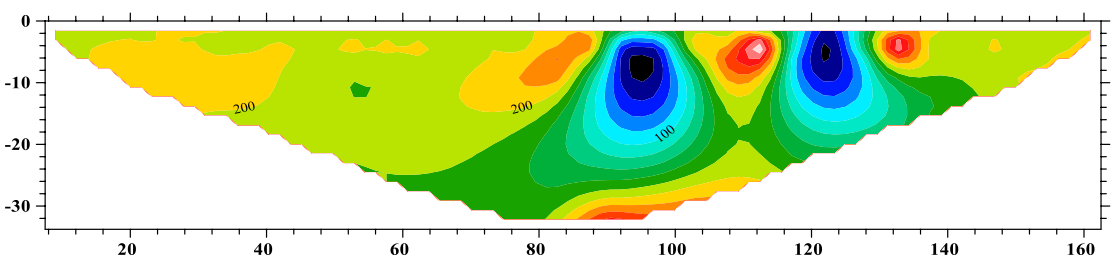

Pole Dipole
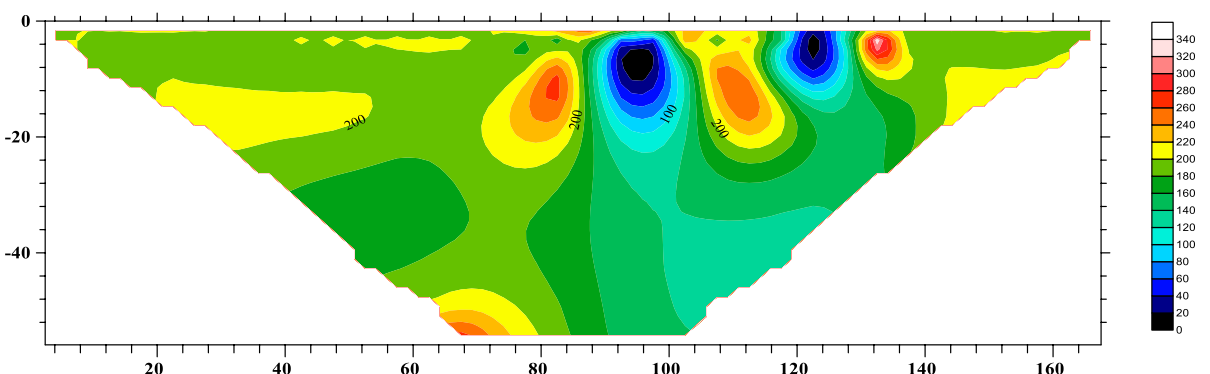

(d)

Wenner Schlumberger

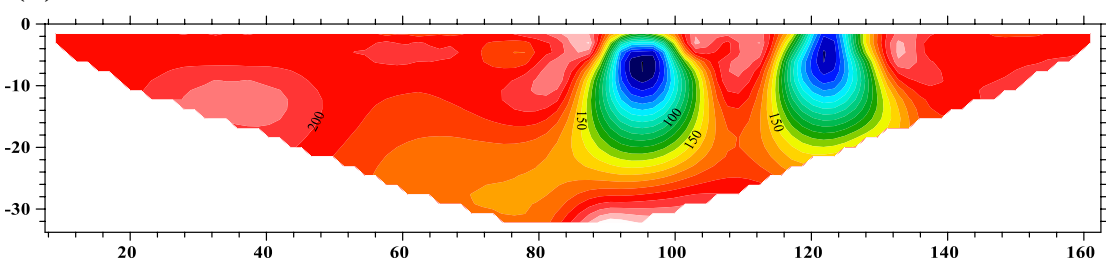

(c)

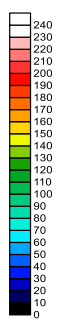

ty (ohm.m)
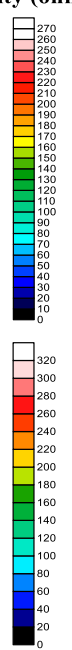

Table 1 Synthetic models characteristics

\begin{tabular}{|c|c|c|c|c|c|c|c|}
\hline Model & $\mathrm{N}^{\circ}$ Data points & $\begin{array}{l}\mathrm{N}^{\circ} \text { Model } \\
\text { blocks }\end{array}$ & $\begin{array}{l}\mathrm{N}^{\circ} \text { Model } \\
\text { layers }\end{array}$ & $\mathrm{N}^{\circ}$ electrodes & $\begin{array}{l}\text { Electrode } \\
\text { spacing }\end{array}$ & $\begin{array}{l}\text { Max pseudo } \\
\text { depth }\end{array}$ & RMS error (\%) \\
\hline Dipole-Dipole & 739 & 286 & 13 & 35 & 5 & 34.6 & 1.67 \\
\hline Pole-Dipole & 974 & 340 & 15 & 35 & 5 & 57.3 & 0.99 \\
\hline Pole-Pole & 319 & 272 & 9 & 35 & 5 & 47.7 & 1.63 \\
\hline Wenner Beta & 187 & 204 & 10 & 35 & 5 & 22.9 & 1.81 \\
\hline Wenner Gamma & 187 & 200 & 10 & 35 & 5 & 32.2 & 1.77 \\
\hline Schlumberger & 527 & 200 & 10 & 35 & 5 & 32.5 & 1.10 \\
\hline Wenner Alpha & 187 & 182 & 9 & 35 & 5 & 28.2 & 1.80 \\
\hline
\end{tabular}


Table 2 Real models characteristics

\begin{tabular}{|c|c|c|c|c|c|c|c|c|}
\hline Model & Inversion & $\mathrm{N}^{\circ}$ Data points & $\begin{array}{l}\mathrm{N}^{\circ} \text { Model } \\
\text { blocks }\end{array}$ & $\begin{array}{l}\mathrm{N}^{\circ} \text { Model } \\
\text { layers }\end{array}$ & $\mathrm{N}^{\circ}$ electrodes & $\begin{array}{l}\text { Electrode } \\
\text { spacing }\end{array}$ & $\begin{array}{l}\text { Max pseudo } \\
\text { depth }\end{array}$ & RMS Error (\%) \\
\hline Palm1 & Robust & 120 & 177 & 8 & 36 & 5 & 25.6 & 7.2 \\
\hline Palm2 & Least square & 123 & 180 & 8 & 36 & 5 & 25.6 & 1.9 \\
\hline Palm3 & Robust & 115 & 170 & 8 & 35 & 5 & 25.6 & 4.3 \\
\hline Palm5 & Least square & 117 & 172 & 10 & 35 & 7.5 & 38.4 & 4.3 \\
\hline Palm6 & Least square & 115 & 169 & 10 & 35 & 7.5 & 38.4 & 4 \\
\hline
\end{tabular}

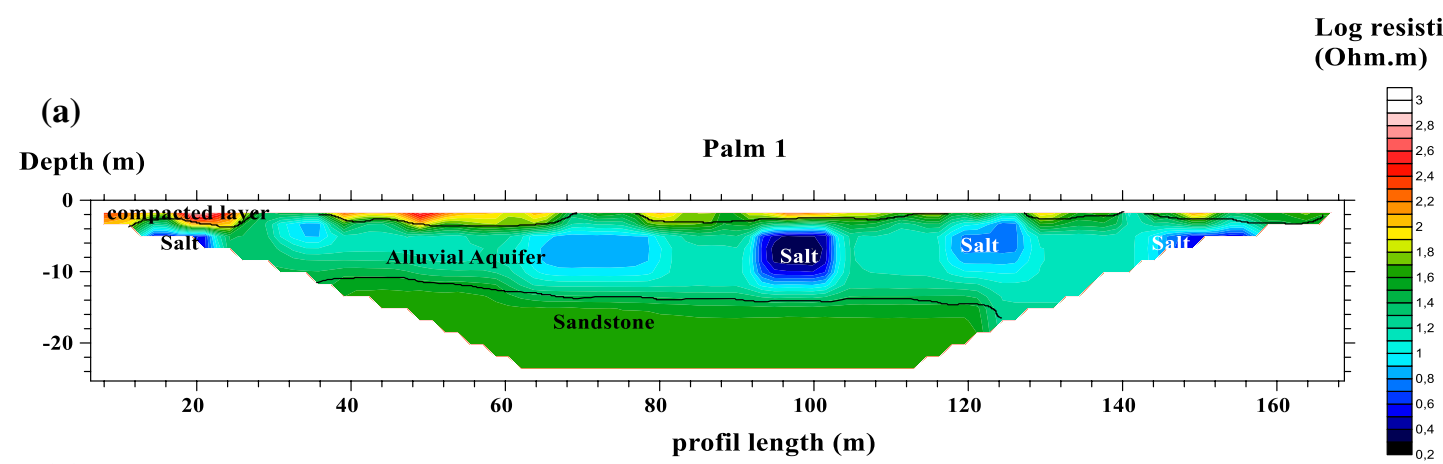

(b)

Depth (m)

Palm 2

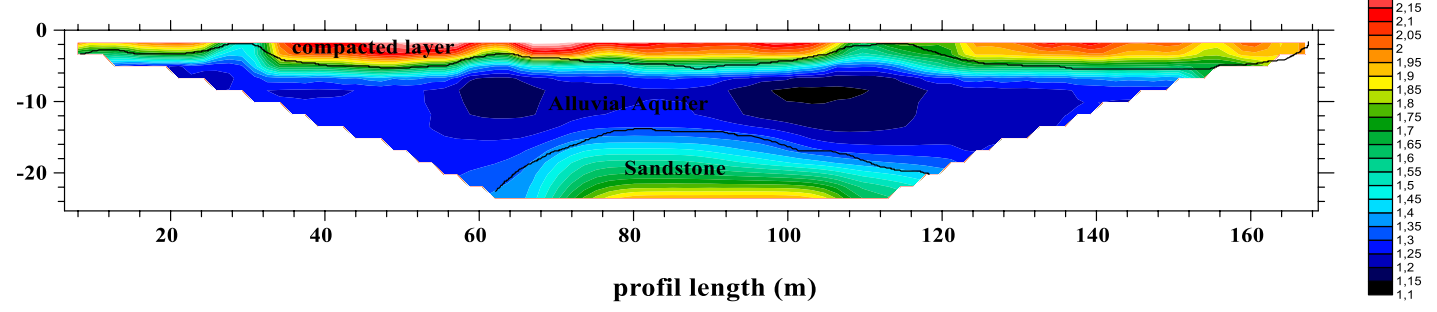

Fig. 6 2D Electric tomography for profiles palm 1 and palm 2

$4 \mathrm{~m}$ for the salt body 2 and $100 \mathrm{~m}$, and $8-18 \mathrm{~m}$ for the salt body 3 . The sandstone layer is located at $20 \mathrm{~m}$ depth with resistivity values of 25-40 $\Omega \mathrm{m}$ (Fig. 7).

\section{Profile palm 5}

The profile 5 is located in the eastern part of the study area and oriented to the NW direction, the electrodes spacing is $7.5 \mathrm{~m}$ and the total length is $245 \mathrm{~m}$, and the maximum investigated depth is $38.4 \mathrm{~m}$ from the top to the profile bottom three layers appears.

Discontinued and compacted layer with moderate electric resistivity values (25-60 $\Omega \mathrm{m}$ ) extended from the surface to 4-5 $\mathrm{m}$ depth.
The second layer represents the alluvial aquifer of Guerrara characterized by low resistivity $(5-10 \Omega \mathrm{m})$ due to the dissolved salts and the water flow direction; the aquifer is thick in the central part of the profile and thin in the East-West parts (Fig. 7).

\section{Profile palm 6}

The profile 6 presents the same geologic structure as the precedent; the alluvial aquifer is characterized by a mean electric resistivity between 2.5 and $10 \Omega$ m without the presence of salt bodies in the geologic formation; the resistivity values indicated the presence of salinity source located in the northern part of the study area; and the 
(a) (Ohm.m)

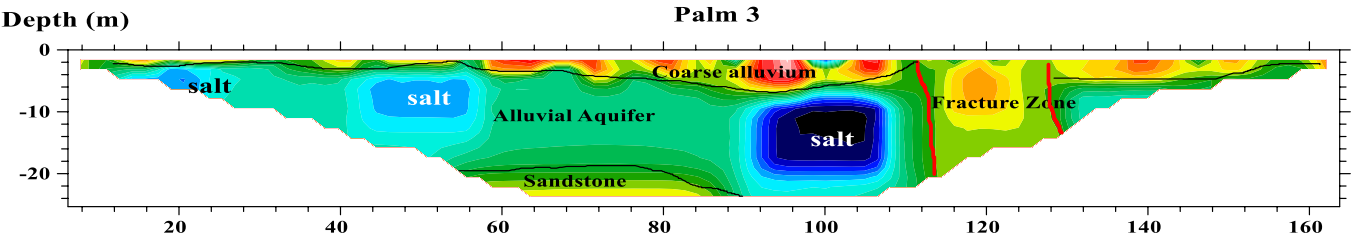

(b)

profil length (m)
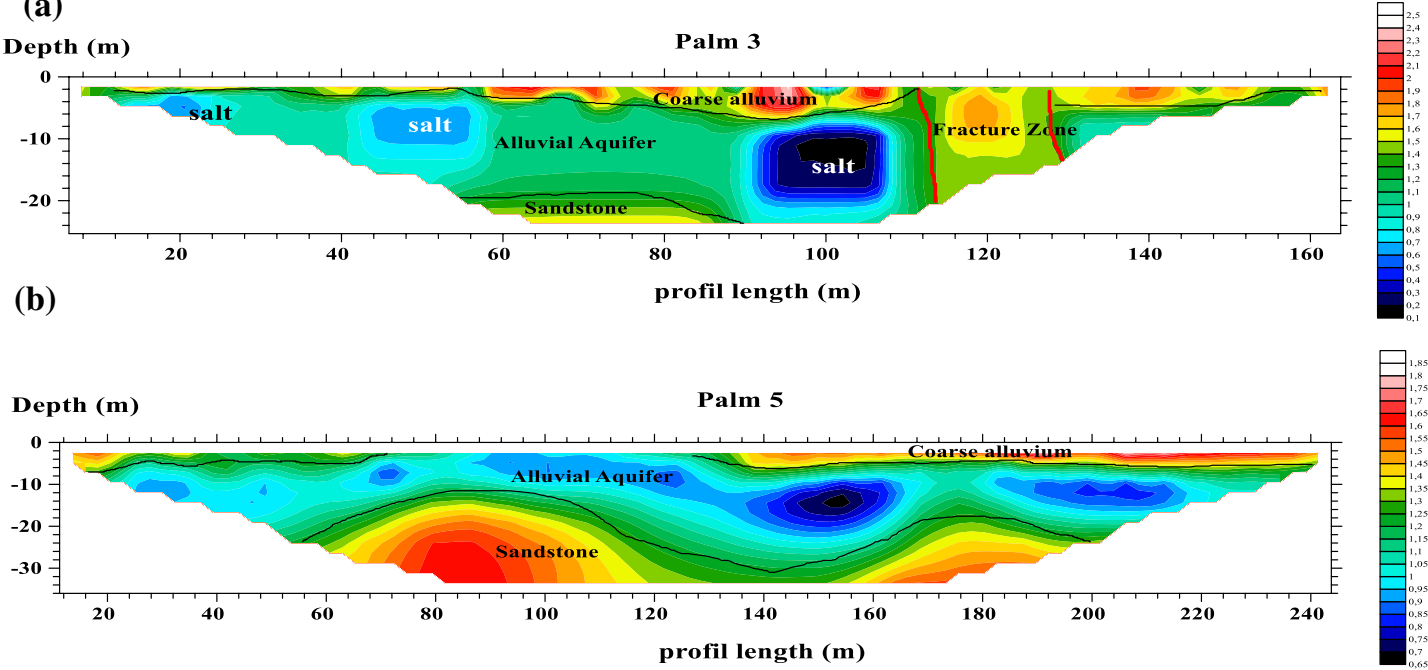

(c)
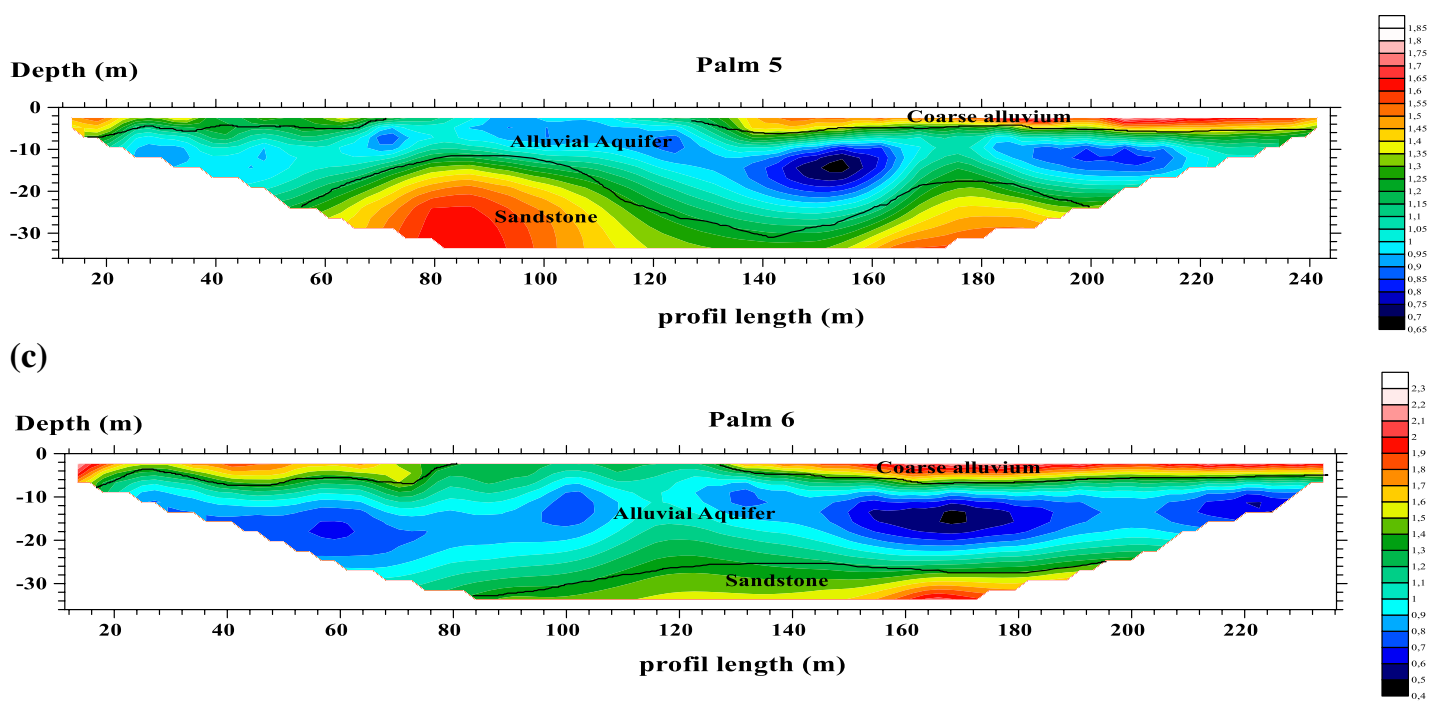

Fig. 7 2D Electric tomography for profiles palm 3, palm 5, and palm 6

sandstone bedrock is at more than $20 \mathrm{~m}$ depth inclined from the NW to SE (Fig. 7).

In this part of the work, 2D forward modeling gives a brief comparison between arrays and technical characteristics that can be used to delineate salt sources affecting the groundwater quality, and the results certify the reliability of the chosen array more than 4 salts bodies are mapped with different volumes (Fig. 8).

\section{Conclusion}

The forward modeling approach is used in this work to examine the arrays geometry to delineate artifacts resulting from salt bodies in aquifer sediments, the tested model gives different responses using standard least square inversion algorithm, and the contrast between the two layers is identified in all the tested arrays but with different degrees of precision.

The results of the simulation show that the Wenner $\alpha$ and Wenner-Schlumberger arrays are better-suited imaging evaporate heterogeneity in alluvial sediments, more arrays are tested for instance DD array producing artifacts and give important artifact values in addition to the time data acquisition, and PP and PD arrays give poor results and are not used in 2D electric tomography imaging.

Additional work is needed to evaluate the contrast in resistivity in different conditions with non-conventional arrays such the extended Dipole-Dipole or modified PoleDipole, or gradient arrays.

The application of the simulation results to the real datasets is critical for the preservation of the hydrogeologic potentialities in the northern part of the Algerian Sahara. Many resistivity contrast are identified in the aquifer alluvium showing the presence of evaporate material contaminating the surface water resources and influencing the suitability for domestic, irrigation, and industrial purpose, for this the future drills of water wells will be uphill the palm grove area which is an ideal zone for salt accumulation. 


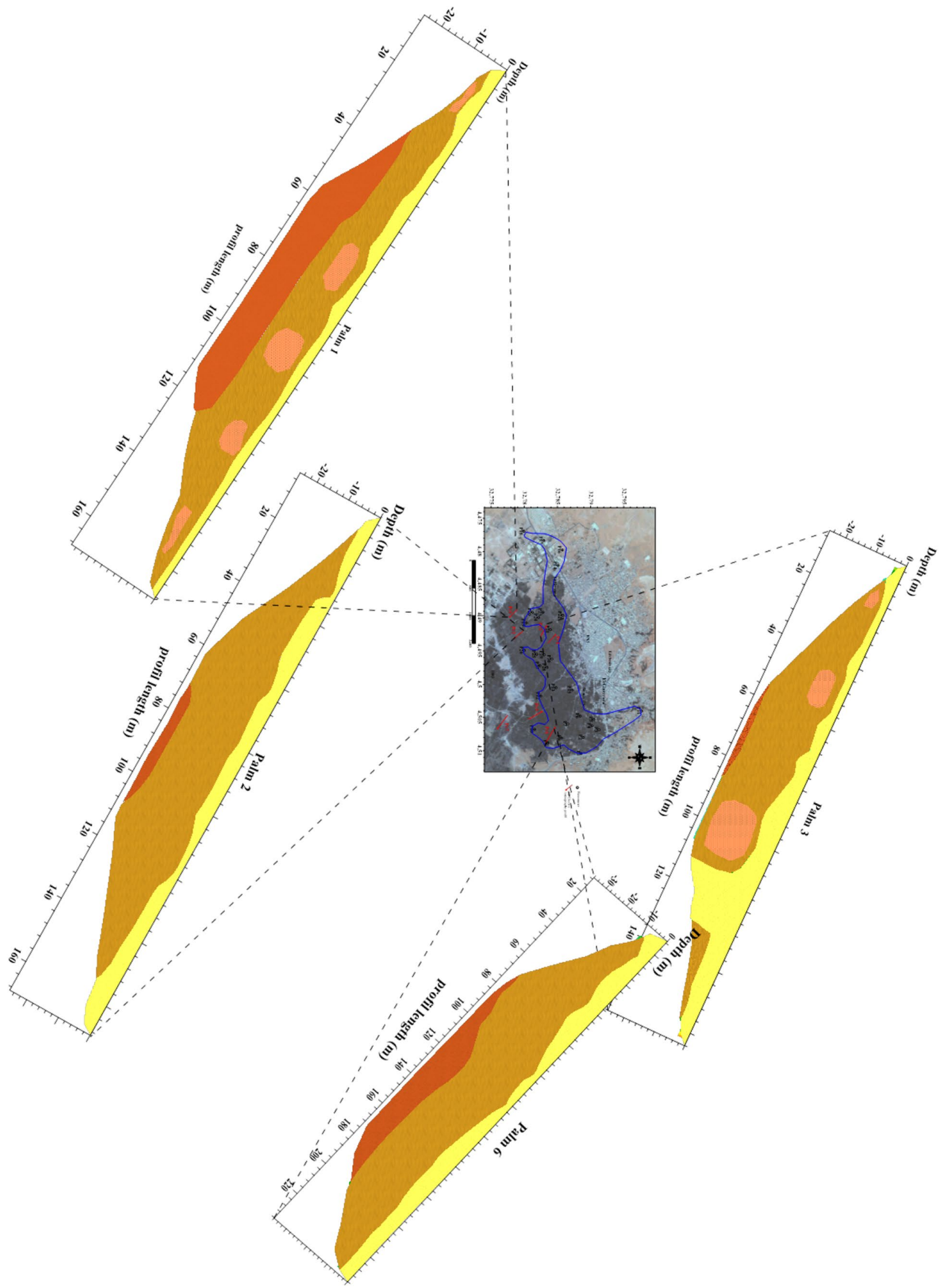

Fig. 8 Geologic model obtained from the interpretation of the 2D electric profils 
Acknowledgements In terms of this work, the authors would like to thank the National Agency of Hydrogeologic Resources Ouargla (ANRH Ouargla) for the help given.

Funding No source funding.

\section{Compliance with ethical standards}

Conflict of interest No conflict of interest.

Open Access This article is licensed under a Creative Commons Attribution 4.0 International License, which permits use, sharing, adaptation, distribution and reproduction in any medium or format, as long as you give appropriate credit to the original author(s) and the source, provide a link to the Creative Commons licence, and indicate if changes were made. The images or other third party material in this article are included in the article's Creative Commons licence, unless indicated otherwise in a credit line to the material. If material is not included in the article's Creative Commons licence and your intended use is not permitted by statutory regulation or exceeds the permitted use, you will need to obtain permission directly from the copyright holder. To view a copy of this licence, visit http://creativecommons.org/licenses/by/4.0/.

\section{References}

Adhikary PP, Chandrasekharan H, Dubey SK, Trivedi SM, Dash CJ (2015) Electrical resistivity tomography for assessment of groundwater salinity in west Delhi, India. Arab J Geosci. https://doi. org/10.1007/s12517-014-1406-y

Carey A, Paige G, Carr B, Dogan M (2017) Forward modeling to investigate inversion artifacts resulting from time-lapse electrical resistivity tomography during rainfall simulations. J Appl Geophys. https://doi.org/10.1016/j.jappgeo.2017.08.002

Dahlin T, Zhou B (2004) A numerical comparison of 2D resistivity imaging with ten electrode arrays. Geophys Prospect 52:379-398

Dey A, Morrison HF (1979) Resistivity modeling for arbitrarily shaped three-dimensional structures. Geophysics 44:615-632

Loke MH (1994) The inversion of two-dimensional resistivity data. Unpubl. PhD thesis. Un. Of Birmingham

Loke MH (2001) Constrained time-lapse resistivity imaging inversion. Proceedings of the Symposium on the Application of Geophysics to Engineering and Environmental Problems (SAGEEP). EEGS. Denver Colorado

Loke MH, Barker RD (1996) Rapid least-squares inversion of apparent resistivity pseudo sections using a quasi-Newton method. Prosp, Geophy. https://doi.org/10.1111/j.1365,2478.tb00142.x

Marescot L (2004) Forward and inverse resistivity modelling on complex three dimensional structures using the finite element method. Doctorat thesis. Université de Nantes

Nguyen F, Kemna A, Antonsson A, Engesgaard P, Kuras O, Ogilvy $\mathrm{R}$, Gisbert J et al (2009) Characterization of seawater intrusion using 2D electrical imaging. Near surface geophysics. https://doi. org/10.3997/1873-0604.2009025

Rao GT, Rao VVSG, Padalu G, Dhakate R, Sarma VS (2013) Application of electrical resistivity tomography methods for delineation of groundwater contamination and potential zones. Arab J Geosci. https://doi.org/10.1007/s12517-013-0835-3

Smith NC, Vozzof K (1984) Two dimensional DC resistivity inversion for dipole-dipole data. IEEE Transactions on Geosciences and Remote Sensing 22(1):21-28

Sumanovac F, Weisser M (2001) Evaluation of resistivity and seismic methods for hydrogeological mapping in karst terrains. J Appl Geophys. https://doi.org/10.1016/S0926-9851(01)00044-1

Publisher's Note Springer Nature remains neutral with regard to jurisdictional claims in published maps and institutional affiliations. 